\title{
On the Strengthening of Cement Mortar by Natural Fibers
}

\author{
Marcos Venicius Pereira ${ }^{a}$, Roberto Fujiyama ${ }^{b}$, Fathi Darwish ${ }^{c}$, Gilvania Terto Alves ${ }^{a}$ \\ ${ }^{a}$ Department of Materials Engineering, Catholic University of Rio de Janeiro - PUC-Rio, \\ Rua Marquês de São Vicente, 225, CEP 22453-900, Rio de Janeiro, RJ, Brazil \\ ${ }^{b}$ Department of Mechanical Engineering, Pará Federal University - UFPA, Rua Augusto Corrêa, 1, \\ CEP 66075-110, Belém, PA, Brazil \\ ${ }^{c}$ Department of Civil Engineering, Fluminense Federal University - UFF, Rua Passo da Pátria, 156, \\ CEP 24210-240, Niterói, RJ, Brazil
}

Received: June 26, 2014; Revised: January 7, 2015

\begin{abstract}
The purpose of this work is to evaluate mechanical behavior of sisal fiber reinforced cement mortar. The composite material was produced from a mixture of sand, cement and water. Sisal fibers were added to the mixture in two different lengths. Mechanical characterization of the composite and the plain mortar was carried out using three point bend, compression and impact tests. Specimens containing parallel sided notches of different root radii were loaded in three point bending in order to determine the effect of the fibers on the material fracture toughness in the presence of discontinuities. According to the results, while fiber reinforcement leads to a decrease in compressive strength, J-integral calculations at maximum load for the different notch root radii have indicated, particularly for the case of long fibers, a significant superiority of the reinforced material in comparison with the plain cement mortar, in consistence with the impact test data.
\end{abstract}

Keywords: composite material, impact energy, fracture initiation, J-integral

\section{Introduction}

It is well known that the presence of short randomly dispersed fibers in a cementitious matrix can result in an appreciable improvement in the mechanical behavior of the produced composite. This improvement is clearly manifested by the significant superiority of the composite's toughness in comparison with that of the plain matrix. The increase in toughness, due to the incorporation of fibers, can be attributed, largely, to the fiber bridging mechanism, whereby the fibers take an active part in supporting tensile loading, in controlling matrix microcracking and in reducing the rate of crack propagation. The fiber reinforced concrete will, therefore, exhibit a pseudoductile behavior, maintaining considerable load carrying capacity after cracking of the matrix.

Different types of fibers, both metallic and nonmetallic, have been used as reinforced elements in cementitious matrices. More specifically, a number of investigations ${ }^{1-4}$ were conducted using randomly dispersed short steel fibers, polymeric fibers and hybrid combinations of both. One could verify that the presence of fibers in, for example, high strength concrete resulted in enhancing both its flexural strength and toughness. This was attributed to energy absorbing mechanism (bridging action) and to delay in microcrack formation ${ }^{1}$.

Environmental awareness and an increasing concern with greenhouse effect have stimulated several industries to look for sustainable substitutes that can replace conventional synthetic fibers. In this respect, natural fibers seem to be a

*e-mail: marcospe@puc-rio.br good alternative to steel and polymeric fibers since they are readily available in fibrous form and can be easily extracted from their proper plants at very low cost ${ }^{5}$. Further, their adoption as reinforcing elements is also associated with overall reduction in $\mathrm{CO}_{2}$ emissions as well as reduced amounts of energy needs ${ }^{5}$.

Starting early seventies, a number of studies ${ }^{6-10}$ have been made regarding the use of natural fibers, such as sisal and bamboo, as reinforcing elements in cement mortars and in concretes. The focus in these works has been on the evaluation of the mechanical properties of the resulting composites as a function of the characteristics of their constituents, and the results obtained have indicated the viability of using natural fibers as reinforcing agents. Cement composite laminates reinforced with long sisal fibers, manufactured using a cast hand lay up technique, were found to exhibit high energy absorbing capacity reflected in high toughness values under tension and bending loads ${ }^{11}$. Ultimate strength, on the other hand, achieved average levels of 12 and $25 \mathrm{MPa}$ for tensile and bend loading, respectively ${ }^{11}$.

It can thus be stated that, despite a tolerable degradation in their compressive strength, flexural strength and fracture toughness of the reinforced composites were significantly enhanced due to the presence of natural fibers, consistent with experimental data reported by Abu-Lebdeh and coauthors ${ }^{3}$. It is to be noted, though, that the susceptibility of natural fibers to degradation, due to ambient and biological factors, requires appropriate surface treatment in order to improve their durability. For example, long 
term embrittlement can be markedly reduced by immersing sisal and coconut fibers in a silica fume slurry prior to their incorporation by the cementitious matrix ${ }^{12}$. Long term properties of the treated specimens were thus found to be very proximate to those of 28 days untreated apecimens ${ }^{12}$.

In view of their numerous advantages, natural fiber reinforced composites have been considered as potential candidates for structural applications, such as low cost residential compounds in developing countries. Structural components are expected to support the applied loads without suffering critical or subcritical fracture during their projected lifetime, and since the presence of discontinuities (notches and cracks) can lead to premature failure, the cement base composite should be tolerant to such defects. The notch sensitivity exhibited by a given material depends on its toughness level and this in turn can be expressed by appropriate parameters such as the value of the J-integral at physically significant events (for example, fracture initiation and maximum load attainment). Higher toughness signifies lower notch sensitivity; however, one should point out that toughness level depends on the notch geometry, particularly the notch root radius.

The present work was initiated with the purpose of evaluating the effect of sisal fibers on the compressive strength and fracture resistance of hardened cement mortar. As the presence of natural fibers is generally detrimental to the compressive strength, it is imperative to strike a good balance of properties, so as to guarantee adequate toughness level together with acceptable compressive strength. For evaluating the fracture toughness, the J-integral approach was adopted and specimens containing deep notches of different root radii were cast in appropriate molds, cured and then loaded in three point bending. The J-integral values at maximum load were determined and correlated with the notch root radius, for both plain and reinforced mortars. Finally, the J-integral results are also correlated with the impact energy of unnotched prismatic bars having the Charpy dimensions.

\section{Material and Methods}

The mortar mixture used in the present study was composed of Portland cement PC 32, washed dry sand and tap water, in the proportions of 1:1: 0.4 , respectively. The sand had fineness modulus of about 3.33, a maximum particle size of $2 \mathrm{~mm}$ and an apparent density of $1.6 \mathrm{~g} / \mathrm{cm}^{3}$.

As to the production of the reinforced mortars, 25 and $45 \mathrm{~mm}$ long sisal fibers, amounting to $3 \%$ of the combined weight of cement and sand, were thoroughly dispersed throughout the dry mixture before water was gradually added. The fibers had an average specific weight of $9.1 \mathrm{kN} / \mathrm{m}^{3}$ and average mechanical properties of $400 \mathrm{MPa}$ tensile strength, $4 \%$ elongation and $18 \mathrm{GPa}$ elastic modulus ${ }^{5}$.

The mixing process resulted in a homogeneous pulp which was cast in appropriate molds for compression and bend test specimens. Twenty four hours later, the specimens were taken off the molds and then immersed in water for 35 days. The hardened specimens of the reinforced mortars had a fiber volume fraction of about 0.081 , corresponding to the quantity of fibers incorporated by the matrix.
Compressive strength of the mortars in question was determined using cylindrical specimens $(50 \mathrm{~mm}$ in diameter and $100 \mathrm{~mm}$ in length) which were loaded at room temperature $\left(23^{\circ} \mathrm{C}\right)$ in a universal testing machine with a cross-head speed of $10^{-5} \mathrm{~m} / \mathrm{s}$.

The fracture resistance of the mortars was evaluated making use of notched prismatic specimens $(50 \times 50 \times 300 \mathrm{~mm})$ which were submitted to three point bending, with $270 \mathrm{~mm}$ loading span. The bend test was carried out at room temperature at a cross head speed of $2 \times 10^{-5} \mathrm{~m} / \mathrm{s}$ and loaddisplacement $(P-\delta)$ curves were obtained for both plain and reinforced mortars. The bend specimens contained a $25 \mathrm{~mm}$ deep parallel sided notch with $0.5,1,1.5,2$ and $2.4 \mathrm{~mm}$ root radius. Unnotched specimens with a geometry identical to that of the notched bars were also tested in three point bending.

Impact testing was carried out on unnotched prismatic specimens $(10 \times 10 \times 50 \mathrm{~mm})$, using a low capacity Charpy type impact machine appropriate for low toughness brittle materials.

\section{Results and Discussion}

\subsection{Compressive strength}

Plain mortar specimens loaded in compression suffered a highly unstable mode of failure, whereas the fiber-reinforced mortars exhibited a more stable behavior, characterized by larger deformations with a gradual drop in the applied load. This increased capacity for deformation can be attributed to the interfacial bond between the sisal fibers and the cement mortar matrix.

The values of the compressive strength were calculated from the ultimate load and are presented in Table 1, for the three mortars in question.

From this table it can be verified that the presence of sisal fibers has a deleterious influence on the strength level. Moreover, this influence turns out to be more significant for the long fibers in comparison with the shorter ones. This can be attributed to a decrease in the mortar's density, associated with an increase in its porosity ${ }^{10-13}$ However, it should be mentioned that the specimen integrity was preserved over a wider deformation range in the presence of longer fibers.

To a first approximation, the ultimate compressive strength of the composite can be estimated from the relation

$\sigma_{C}=V_{M} \sigma_{M}$

where $\sigma_{C}$ and $\sigma_{M}$ are respectively the composite and matrix strength and $V_{M}$ the matrix volume fraction given by

$V m=(1-V f)$

where $V_{F}$ is the fiber volume fraction.

Table 1. Compressive strength of the plain and reinforced mortars.

\begin{tabular}{lc}
\hline \multicolumn{1}{c}{ Mortar } & $\begin{array}{c}\text { Compressive Strength } \\
\text { (MPa) }\end{array}$ \\
\hline plain & $28 \pm 1$ \\
reinforced with $25 \mathrm{~mm}$ sisal fibers & $25 \pm 1$ \\
reinforced with 45 mm sisal fibers & $22 \pm 1$ \\
\hline
\end{tabular}


The validity of Equation 1 is derived from the hypothesis that the fibers do not play an active role in supporting compressive loads applied to the composite. Accordingly, for the sisal fiber volume fraction of $0.081, \sigma_{C}$ is estimated to be about $25.7 \mathrm{MPa}$, which is close to the compressive strength level of $25 \mathrm{MPa}$ experimentally determined for the mortar containing the $25 \mathrm{~mm}$ fibers. However, for the long fibers (45 mm), the lower compressive strength of $22 \mathrm{MPa}$ listed in Table 1 does not agree well with the strength level estimated by Equation 1, indicating that higher porosity can be associated with the incorporation of such fibers.

\subsection{Flexural strength}

As expected, the use of sisal fibers as reinforcing element resulted in a significant increase in the load carrying capacity of the unnotched bend specimens. The ultimate load values, corresponding to the average of three bend tests, amounted to $1.5,2.2$ and $2.5 \mathrm{kN}$, for the plain, $25 \mathrm{~mm}$ and $45 \mathrm{~mm}$ fiber reinforced mortar, respectively. Considering the specimen geometry and dimensions, the maximum flexural stress $\sigma$, within the linear elastic loading regime, can be related to applied load $P$ as

$\sigma=3.24 P$

where $P$ is in $\mathrm{kN}$ and $\sigma$ in $\mathrm{MPa}$.

Equation 3, which is based on the theory of beams, can be applied to the plain mortar, as it behaves essentially in an elastic manner, yielding a flexural strength level of about $5 \mathrm{MPa}$. To a first approximation, the same equation may also be applied to the fiber reinforced mortars, resulting in strength levels of about 7 and $8 \mathrm{MPa}$, for the 25 and $45 \mathrm{~mm}$ fiber reinforcement, respectively. These values are considered to be rough estimates, in virtue of the nonlinear behavior that precedes the ultimate load achieved by the fiber reinforced bend specimens. Accordingly, one may be able to conclude that the reinforced mortar can achieve a flexural strength level, representing a $60 \%$ improvement over the plain matrix of similar formulation. A common theme in the literature ${ }^{14-15}$ refers to the notion that fibers serve as bridging elements when crack traverses the cement matrix, thus maintaining the specimen integrity and allowing the ultimate load and deformation capacity to increase.

The strengthening effect due to fiber presence is also related to the interfacial bond between the fibers and cement matrix, which allows the former to take an active part in supporting the applied load. Sisal fibers present irregular cross section with different shapes that may be beneficial for the bond strength. Three different cross sectional geometries were reported in the literature ${ }^{16}$ : horse-shoe, arched and twisted arch shape, with the highest bond stress related to the twisted arch fiber type. Average adhesional bond for all three cross sectional geometries is reported to be in the range of 0.59 to $0.67 \mathrm{MPa}^{16}$.

Macro and micro fracture aspects of fiber reinforced bend specimens are presented in Figures 1 and 2. As depicted in Figure 1, fracture mode of the fiber reinforced bend specimens is characterized by a pull-out failure mechanism. This figure refers to the profile of a $45 \mathrm{~mm}$ fiber reinforced specimen, showing the sisal fibers as exposed due to fiber pull-out. Figure 2, on the other hand, presents the fracture surface features of a $25 \mathrm{~mm}$ fiber reinforced bend specimen, also attesting to the pull-out phenomenon as a dominant mode of failure. At this point, it is important to mention that the pull-out force increases as the embedded fiber length increases ${ }^{16}$, which is seen to be consistent with the fact that long $(45 \mathrm{~mm})$ fibers are more effective in promoting flexural strength than the $25 \mathrm{~mm}$ fibers.

\subsection{Fracture resistance}

Examples of the load-displacement curves obtained in three point bending of the composite mortar are presented in Figure 3, for the different notch root radii. The loaddisplacement curves corresponding to the plain and reinforced mortars are depicted in Figures 4, 5 and 6, for the $0.5,1.5$ and $2.4 \mathrm{~mm}$ root radii, respectively, indicating the marked influence of the presence of sisal fibers on both load carrying capacity and deformability of the notched specimens.

The variation of the maximum load, $P_{U}$, with the notch root radius, $\rho$, is presented in Figure 7, for the mortars in question. Compared to their respective unnotched counterparts, the notched specimens had a much lower load

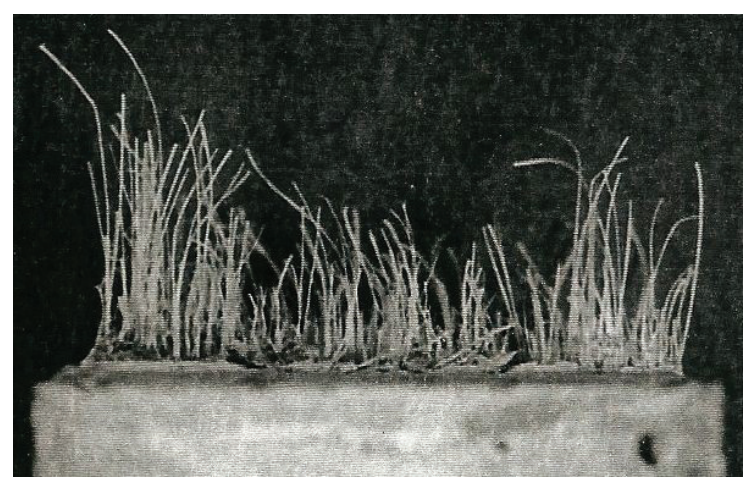

Figure 1. Fracture profile of a $45 \mathrm{~mm}$ fiber reinforced specimen.

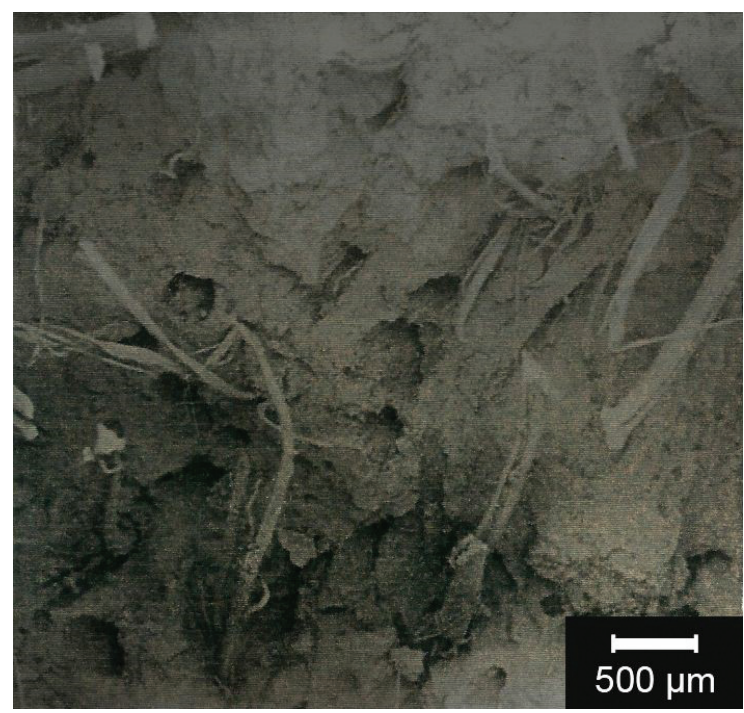

Figure 2. Fracture surface of a $25 \mathrm{~mm}$ fiber reinforced bend specimen. 
carrying capacity, as a result of the significant reduction of the specimen cross section in the notch plane. As to the influence of the notch root radius, Figure 7 indicates that $P_{U}$ decreases as the notch becomes sharper and that, for a given root radius, the incorporation of the sisal fibers is associated with an appreciable increase in the load carrying capacity, with the long fibers being more effective in that respect. This is seen to be consistent with the results obtained on the flexural strength of unnotched beams, as sisal fibers contribute significantly to the tensile strength and more effectively so for longer fibers in virtue of the increase in the interfacial force, between fibers and matrix, with the increase in fiber length.

\subsubsection{Toughness estimation}

The J-integral values at maximum load $\left(J_{M}\right)$ were calculated from the integrated energy $(U)$ under the loaddisplacement curve, using the Rice estimation formula ${ }^{17}$.

$$
J=\frac{2 U}{B(W-a)}
$$

where $B$ and $W$ are the specimen cross sectional dimensions $(50 \times 50 \mathrm{~mm}), a$ the notch depth $(25 \mathrm{~mm})$ and $U$ the integrated energy under the $P-\delta$ curve up to $P=P_{U^{*}}$.

At this point, it is important to mention that toughness evaluation of concrete using fracture mechanics is considered to be applicable to large scale initially cracked structures $^{18-19}$, where structural aspects, such as the size of coarse aggregates, are to be small compared to the concrete size. Thus, the effect of specimen size should be considered in determining the fracture toughness of concrete. For the mortars considered in the present study, the relevant microstructural scale, which is related to the

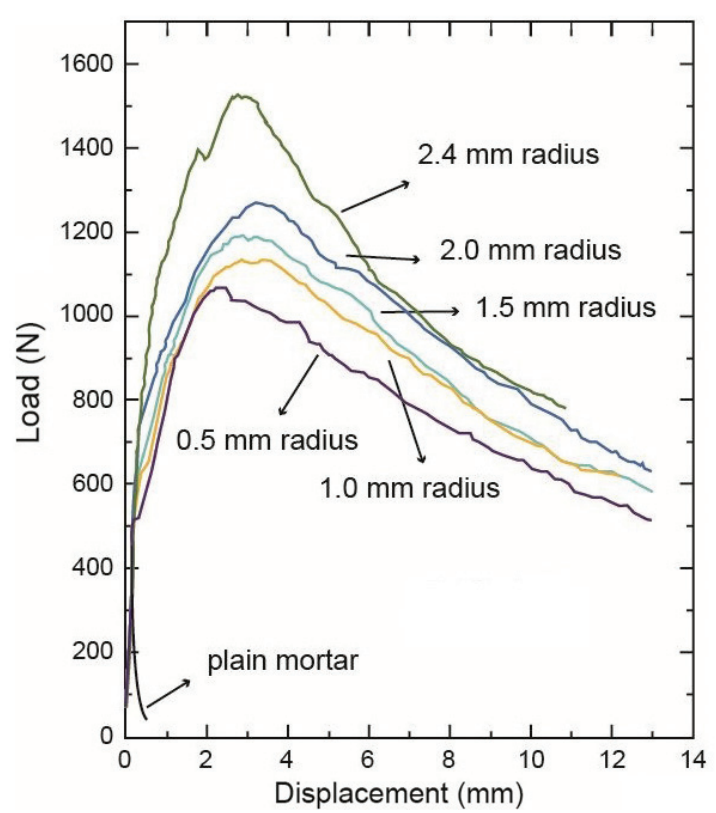

Figure 3. Load-displacement curves of the $45 \mathrm{~mm}$ fiber composite mortar. sand used as aggregate, is in fact very small in comparison to the bend specimen dimensions. Accordingly, Equation 4 is considered to be applicable to toughness determination of cement mortar.

The variation of $J_{M}$ with the root radius is shown in Figure 8, for the plain mortar. One can observe that such a variation is in agreement with the effect normally detected

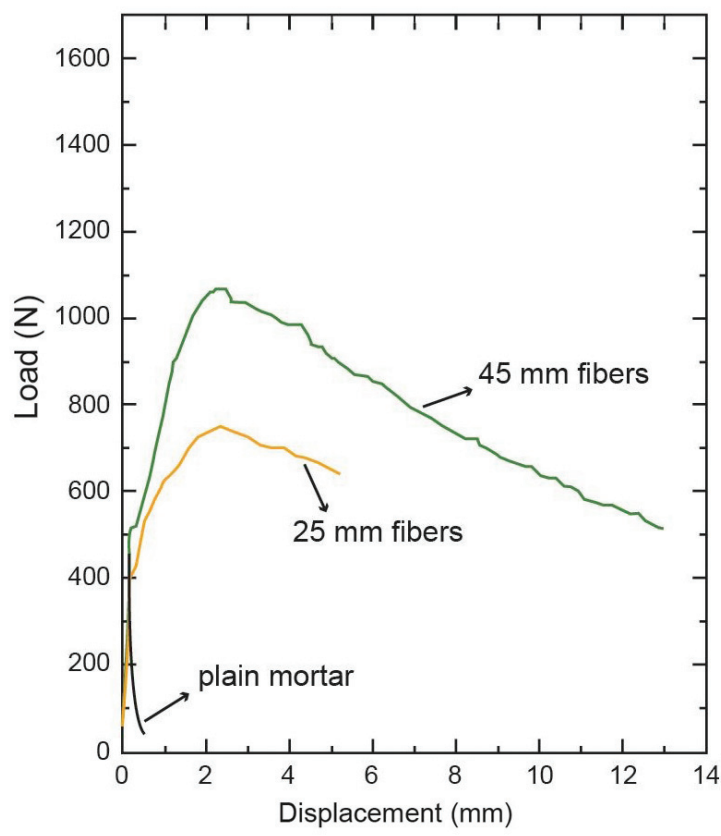

Figure 4. Mortars' load-displacement curves in three point bending for $0.5 \mathrm{~mm}$ root radius.

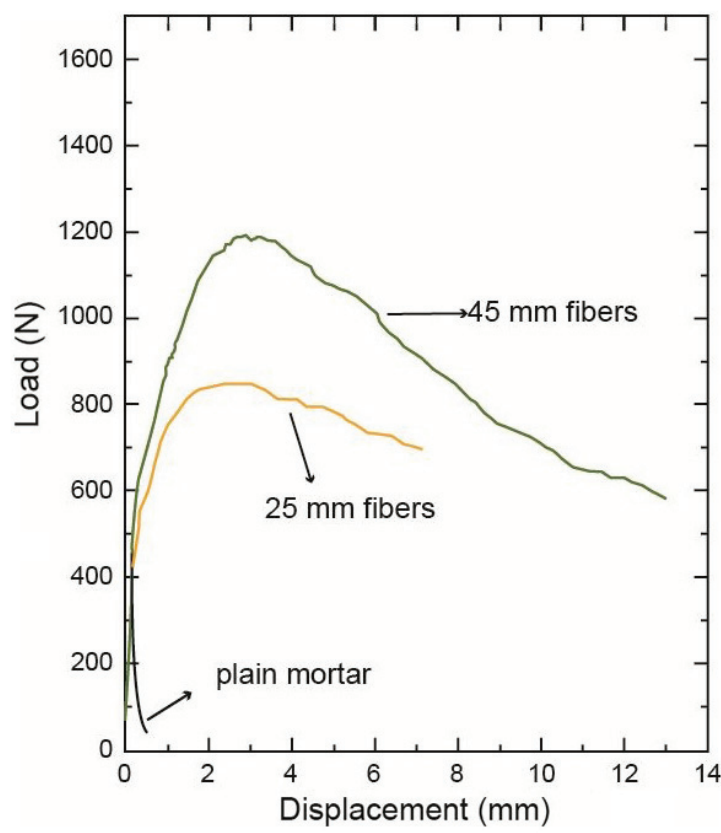

Figure 5. Mortars' load-displacement curves in three point bending for $1.5 \mathrm{~mm}$ root radius. 


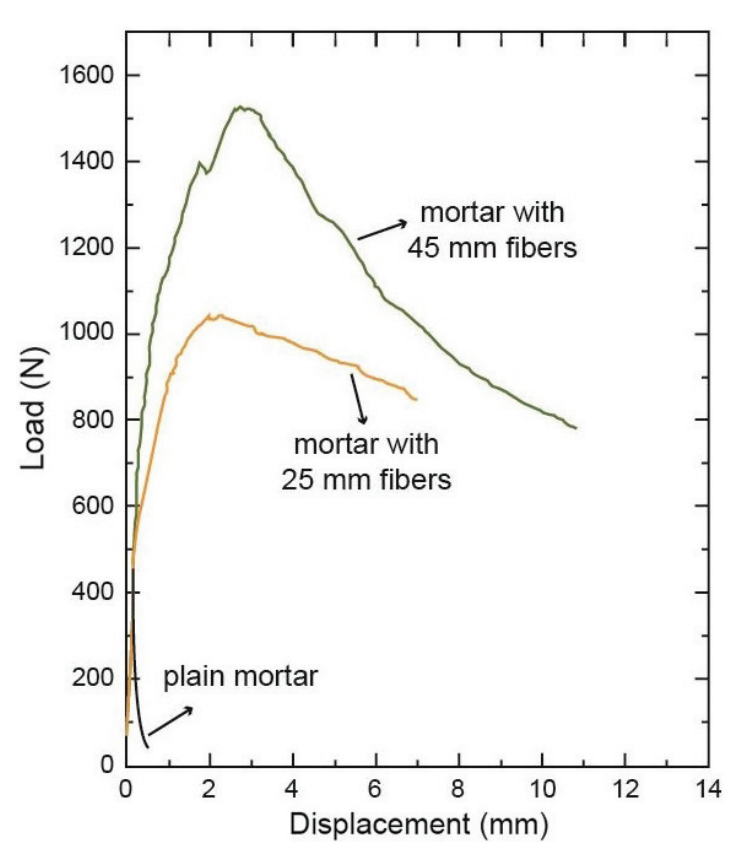

Figure 6. Mortars' load-displacement curves in three point bending for $2.4 \mathrm{~mm}$ root radius.

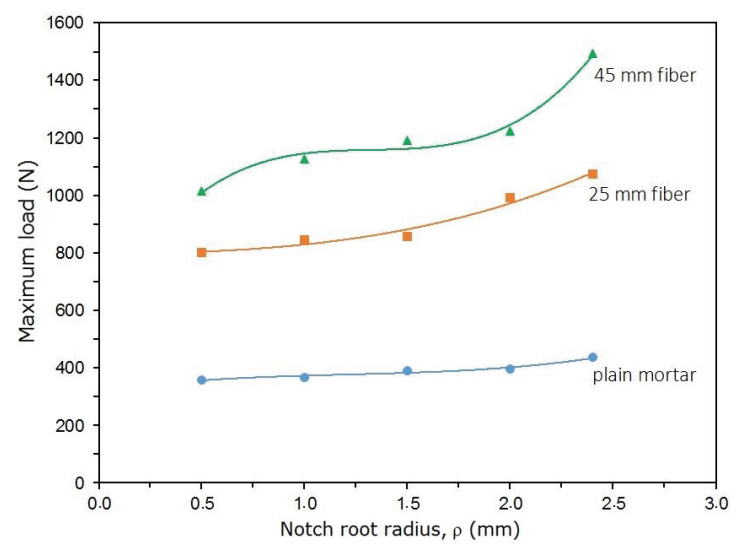

Figure 7. Influence of the notch root radius on the maximum load for the different mortars.

for metallic and nonmetallic materials, where the J-integral value at fracture initiation varies linearly with the root radius. As fracture initiation in the plain mortar occurs essentially at the maximum load, $J_{M}$ can, therefore, be considered a good estimate of the J-integral value corresponding to the event of failure initiation in the mortar. For small root radii $(\rho \leq 1.5 \mathrm{~mm})$, though, $J_{M}$ becomes independent of $\rho$, remaining at a constant level discriminated as $J_{I C}$ and considered as a material characteristic. The limiting root radius, which is equivalent approximately to $1.5 \mathrm{~mm}$, is also considered a material constant of microstructural significance, apparently compatible with the fact that the sand, used as a constituent of the mortar mixture, had a maximum particle size of $2 \mathrm{~mm}$.

As to the reinforced mortars, the variation of $J_{M}$ with the notch root radius is presented in Figure 9, for both the 25 and

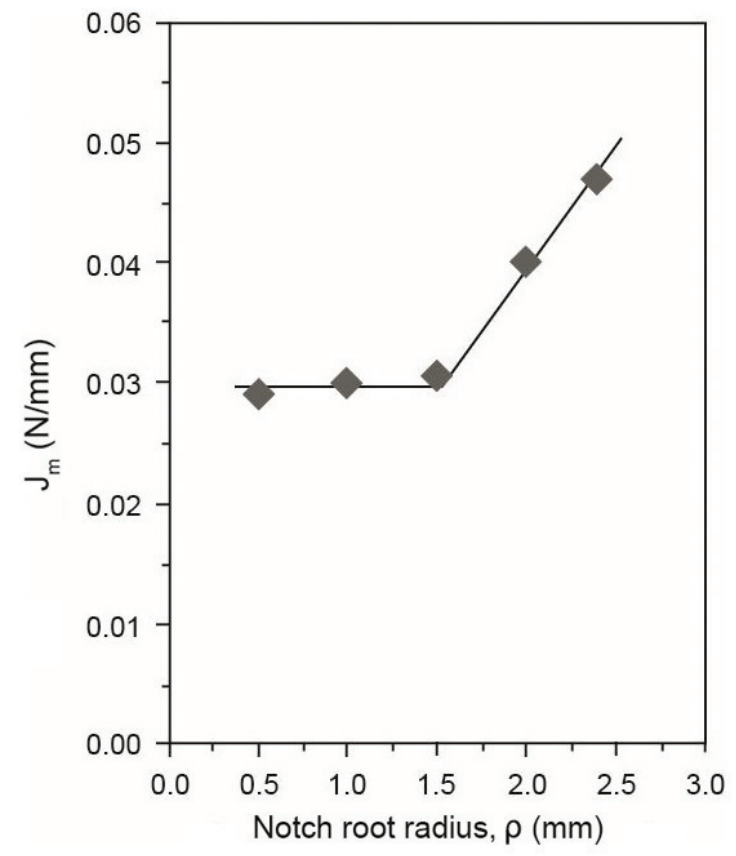

Figure 8. Variation of $J_{M}$ with the notch root radius for the plain mortar.

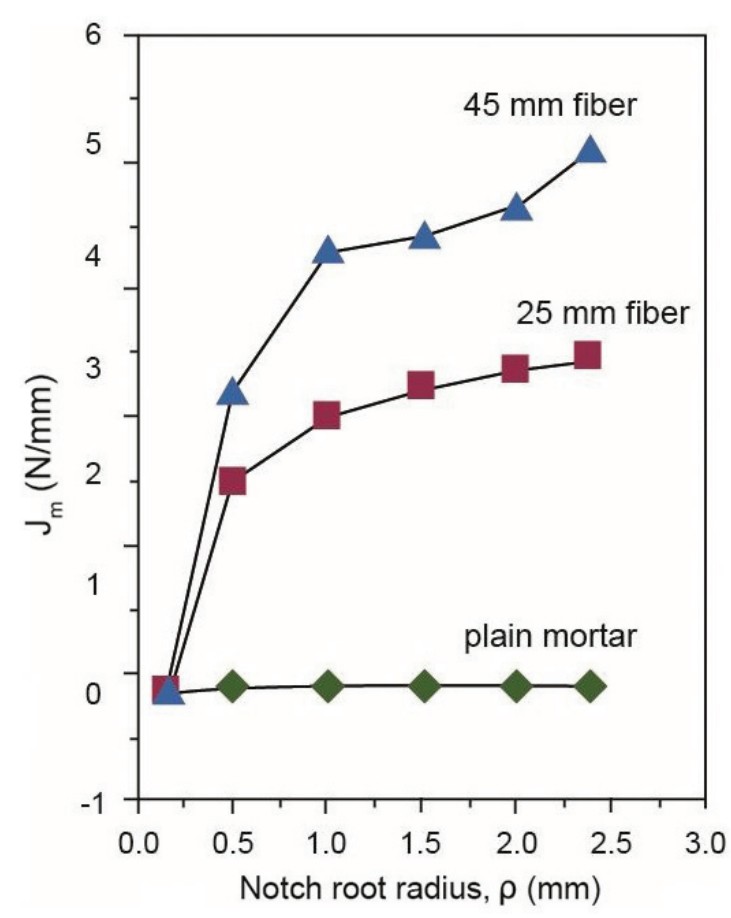

Figure 9. Variation of $J_{M}$ with the notch root radius for the plain and reinforced mortars.

$45 \mathrm{~mm}$ sisal fibers, in comparison with the $J_{M}$ level of the plain mortar. In addition to the extremely beneficial effect of fibers on the mortar's fracture resistance expressed by $J_{M}$, the figure also indicates that a better fracture resistance of the mortar was associated with the use of $45 \mathrm{~mm}$ sisal 
Table 2. Impact energy of the plain and reinforced mortars.

\begin{tabular}{lc}
\hline \multicolumn{1}{c}{ Mortar } & Impact energy $(\mathbf{J})$ \\
\hline plain & $0.45 \pm 0.05$ \\
reinforced 25 & $2.04 \pm 0.22$ \\
reinforced 45 & $3.28 \pm 0.35$ \\
\hline
\end{tabular}

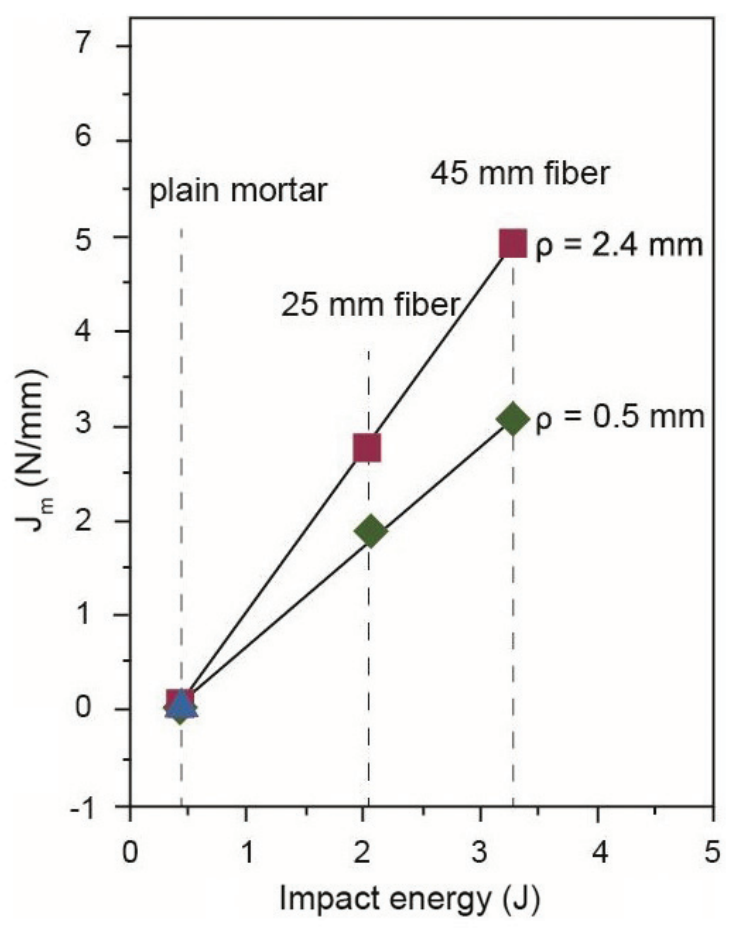

Figure 10. Correlation between $J_{M}$ and impact energy for the reinforced mortars with notch root radius of 0.5 and $2.4 \mathrm{~mm}$.

fibers. The beneficial effect on toughness is the result of an improvement in both strength and ductility of the mortar due to sisal fiber presence and as can be verified from the $P-\delta$ curves, this effect is more pronounced for the longer fibers.

The impact energy results are presented in Table 2, for the three mortars in question. The individual energy levels shown in the table correspond to the average of five tests with a standard deviation of about $12 \%$.

\section{References}

1. Sivakumar A and Santhanam M. Mechanical properties of high strength concrete reinforced with metallic and non-metallic fibers. Cement and Concrete Composites. 2007; 29(8):603-608. http://dx.doi.org/10.1016/j.cemconcomp.2007.03.006.

2. Qian CX and Stroeven P. Development of hybrid polypropylenesteel-fiber-reinforced concrete. Cement and Concrete Research. 2000; 30(1):63-69. http://dx.doi.org/10.1016/S00088846(99)00202-1.

3. Abu-Lebdeh TM, Fini E and Lumpkin M. Flexural and tensile characteristics of microfiber-reinforced very high strength concrete thin panels. American Journal of Engineering
The analysis of Table 2 leads to conclude that the use of sisal fibers as a reinforcing element in mortar results in a considerable increase in the impact resistance and that such an increase is considerably more significant for the longer fibers. Results obtained by Ramakrishna and Sundararajan ${ }^{20}$ have shown that the addition of natural fibers to cement mortar slab can increase its impact resistance by a factor ranging between 3 and 18. This beneficial influence is attributed to the fact that, even as the matrix cracks, the load carrying capacity is replenished by invoking fiber loading. This maintains the specimens' integrity as they continue to deform and hence to absorb more energy. The superiority of long fibers in promoting impact resistance is related to the higher load carrying capacity, as well as deformability, of the mortars reinforced with such fibers.

The correlation between the impact energy levels and J-integral results is presented in Figure 10, whereby an essentially linear relationship is seen to exist between the two parameters.

\section{Conclusions}

Regarding the study described herein, the following conclusions can be drawn:

- The use of sisal fibers decreases the mortar's compressive strength. However, the fiber reinforced mortars exhibit retardation of the failure process, characterized by larger deformations and gradual drop in the applied load, when compared with the plain mortar.

- The deleterious influence of sisal fibers on the compressive strength of reinforced mortar seems to be more significant for long fibers than for shorter ones.

- The presence of sisal fibers in cement mortar considerably improves its fracture resistance. This improvement is manifested by an increase in the J-Integral values determined at maximum load in the presence of deep notches with different root radii.

- Results of impact tests on unnotched specimens indicate a pronounced improvement in impact energy levels due to sisal fibers incorporated to cement mortar.

- Longer sisal fibers are seen to be more effective than shorter ones in promoting fracture resistance of reinforced mortars. and Applied Science. 2012; 5(2):184-197. http://dx.doi. org/10.3844/ajeassp.2012.184.197.

4. Kitamura S. Experimental study of the influence of fiber content and specimen dimensions on the split tensile strength and its relationship with the flexural strength. [Dissertation]. Rio de Janeiro: Fluminense Federal University; 2006. Portuguese.

5. Silva FA, Chawla N and Toledo Filho RD. Tensile behavior of high performance natural (sisal) fibers. Composites Science and Technology. 2008; 68(15-16):3438-3443. http://dx.doi. org/10.1016/j.compscitech.2008.10.001.

6. Fujiyama RT. Sisal fiber reinforced cement mortar-mechanical and microstructural characterization. [Dissertation]. Rio 
de Janeiro: Catholic University of Rio de Janeiro; 1997. Portuguese.

7. Brescansin J. Fracture behavior of bamboo pulp reinforced cementitious matrix. [Dissertation]. Rio de Janeiro: Catholic University of Rio de Janeiro; 2003. Portuguese.

8. Toledo Filho RD. Natural fiber reinforced mortar composites: experimental characterization. [Thesis]. Rio de Janeiro: Catholic University of Rio de Janeiro; 1997.

9. Campello EF. Fatigue behavior of bamboo pulp reinforced cementitious composites. [Dissertation]. Rio de Janeiro: Catholic University of Rio de Janeiro; 2006. Portuguese.

10. Okafor FO, Eze-Uzomaka OJ and Egbuniwe N. The structural properties and optimum mix proportions of palmnut fibrereinforced mortar composite. Cement and Concrete Research. 1996; 26(7):1045-1055. http://dx.doi.org/10.1016/00088846(96)00087-7.

11. Silva FA, Mobasher B and Toledo Filho RD. Cracking mechanisms in durable sisal fiber reinforced cement composites. Cement and Concrete Composites. 2009; 31(10):721-730. http://dx.doi.org/10.1016/j.cemconcomp.2009.07.004.

12. Toledo Filho RD, Ghavami K, England GL and Scrivener K. Development of vegetable fibre-mortar composites of improved durability. Cement and Concrete Composites. 2003; 25(2):185196. http://dx.doi.org/10.1016/S0958-9465(02)00018-5.

13. Hughes BP and Fattuhi NI. Stress-strain curves for fibre reinforced concrete in compression. Cement and Concrete Research. 1977; 7(2):173-183. http://dx.doi.org/10.1016/00088846(77)90028-X.
14. Li VC. J-integral applications to characterization and tailoring of cementitious materials. In: Chuang T-J, Rudnicki JW, editors. Multiscale deformation and fracture in materials and structures. Springer; 2002. p. 385-406.. http://dx.doi. org/10.1007/0-306-46952-9_21.

15. Savastano Jr. H, Turner A, Mercer C and Soboyejo WO. Mechanical behavior of cement-based materials reinforced with sisal fibers. Journal of Materials Science. 2006; 41(21):69386948. http://dx.doi.org/10.1007/s10853-006-0218-1.

16. Silva FA, Mobasher B, Soranokom C and Toledo Filho RD. Effect of fiber shape and morphology on interfacial bond and cracking behaviors of sisal fiber cement based composites. Cement and Concrete Composites. 2011;33(8):814-823. http:// dx.doi.org/10.1016/j.cemconcomp.2011.05.003.

17. Rice JR. A path independent integral and the approximate analysis of strain concentrations by notches and cracks. Journal of Applied Mechanics. 1968; 35(2):379-386. http://dx.doi. org/10.1115/1.3601206.

18. Choi S-H, Kye H-J and Kim W-J. J-integral evaluation of concrete fracture characteristics. International Journal of Concrete Structures and Materials. 2006; 18(3E):183-189. http://dx.doi.org/10.4334/IJCSM.2006.18.3E.183.

19. Jun Z and Qian L. Determination of concrete fracture parameters from a three-point bending test. Tsinghua Science and Technology. 2003; 8(6):726-733.

20. Ramakrishna $G$ and Sundararajan $T$. Impact strength of a few natural fibre reinforced cement mortar slabs: a comparative study. Cement and Concrete Composites. 2005; 27(5):547-553. http://dx.doi.org/10.1016/j.cemconcomp.2004.09.006. 